\section{A window on early animal evolution}

\section{The Cambrian Fossils of Chengjiang, China: The Flowering of Early Animal Life}

by Xian-Guang Hou, Richard J. Aldridge, Jan Bergström, David J. Siveter, Derek J. Siveter \& Xiang-Hong Feng

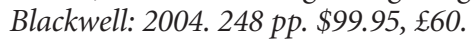

\section{Zhe-Xi Luo}

In the Early Cambrian period (544 million to 520 million years ago) there was a great evolutionary radiation of animal life. Within a short geological time, the vast majority of modern animal phyla (groups defined by their distinctive body plans) appeared in the fossil record worldwide. These early fossils represent the roots for the tree of all modern animal life.

Some of the jewels in the crown of Early Cambrian fossils are embedded in the mudstones of Chengjiang in southern China, where tens of thousands of exceptionally preserved and soft-bodied fossils have been discovered during the past 20 years. More than 130 species of 13 animal phyla have been recognized, and the number of organisms that are new to science is still growing. Aptly subtitled The Flowering of Early Animal Life, this beautifully produced book by XianGuang Hou and colleagues is the best systematic compendium of the entire Chengjiang biota, offering a rare view of this great episode in the diversification of animal life.

The book recounts the serendipitous discovery of this Lagerstätte, or great mother lode, of soft-bodied fossils in 1984. It also describes the persistent exploration over the next two decades by Hou, Jun-Yuan Chen, De-Gan Shu and their many collaborators that revealed the wealth of this site for studies of the early evolution of animal life. Several organisms from Chengjiang are so extraordinary that they cannot easily be placed in any modern animal phylum. For example, Vetulicola looks like a crustacean, judging by its tail, but has gill slits that some palaeontologists would argue indicate chordate affinities. These new fossils further widen the range of body plans for deuterostomes, a lineage that already includes echinoderms (sea urchins), various chordates and vertebrates.

These beautiful and unique fossils have inspired new scientific insights and led to the clashing of ideas. There is a great debate on the likely positions of Chengjiang animals such as the yunnanozoans in the deuterostome family tree. Such debates will surely redefine the phylogenetic framework for establishing the earliest evolution of key features of chordates.

The publication of this book is timely for several reasons. It is not only a fitting

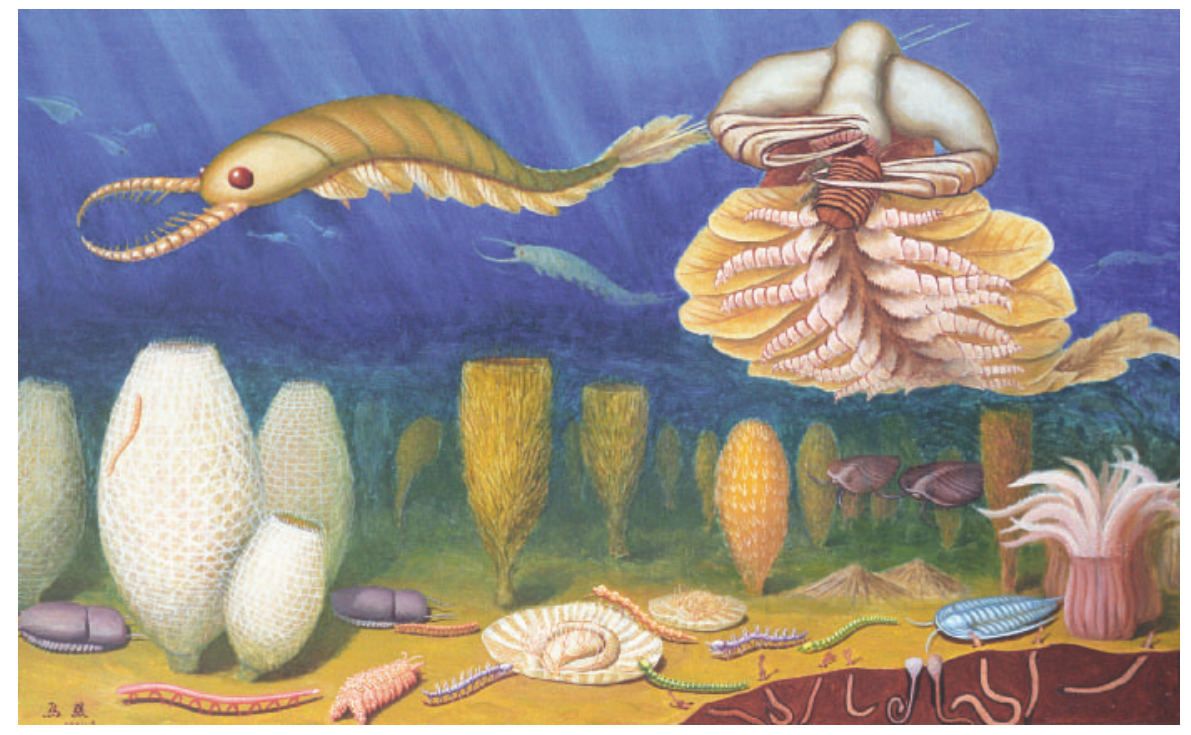

Fossils found at Chengiiang provide evidence of the rapid evolution of a vast range of body plans.

Festschrift to celebrate the twentieth anniversary of Hou's discovery of the Chengjiang Lagerstätte, but it also provides an update on the fast-paced attempts to decipher the full evolutionary significance of this palaeontological treasure. It is also the first review in English on the Chengjiang biota. For palaeontologists and evolutionary biologists whose native tongue is not Chinese, this volume is a useful gateway to a much larger body of literature on the Chengjiang fossils, including some extensive Chinese monographs. For specialists, the book provides an extensive systematic survey of the Chengjiang organisms; each taxon has a synoptic review with key references. For generalists with an interest in early animal evolution, the book offers a concise overview of the geochronology, taphonomy, palaeoenvironment and palaeoecology of the Chengjiang fossil sites. The book is lavishly illustrated with hundreds of colour photographs and accurate artistic rendering of many fossil organisms.

But beyond its utilitarian value as an informative reference resource, the book has much to offer those interested in a multidisciplinary approach to studying early animal evolution. The early animal fossil record, however incomplete, can tell us about the early diversification of major animal lineages, a hot topic for molecular evolutionary studies, especially with regard to the timing of early animal evolution. The Chengjiang fossils are the best source of evidence about the emergence of animal body plans, and have attracted interest from students of evolutionary development.

Many of my colleagues have proclaimed that the Chengjiang mudstone is China's answer to Canada's Burgess Shale. Notwithstanding my fondness for vertebrates, what makes Chengjiang special is the presence of new species of the earliest vertebrates and their putative chordate and deuterostome relatives that are not known elsewhere; the Early Cambrian sea of Chengjiang really is a cradle of early chordate evolution. In such a context, this otherwise quite exhaustive book is a bit limited on what are Chengjiang's highlights: its vertebrates and their putative relatives. The authors cautiously avoided endorsing any of the competing interpretations of several enigmatic organisms, such as Yunnanozoon, almost to a fault.

The book's authors - six experts from five institutions in three countries - are a microcosm of the world community of palaeontologists who have long cherished collaborative research that transcends national boundaries. Such collaborations have accelerated the pace at which the major discoveries from Chengjiang are disseminated to the worldwide scientific community. This has not only won worldwide recognition for China's great fossil treasure, but has made the point that truly great science has no national boundaries.

Zhe-Xi Luo is a curator of vertebrate

palaeontology, Carnegie Museum of Natural History, Pittsburgh, Pennsylvania 15213, USA.

\section{Diagrams you can count on}

\section{Cogwheels of the Mind: the Story of Venn Diagrams}

by A.W. F. Edwards (foreword by Ian Stewart)

Johns Hopkins University Press: 2004.

128 pp. \$25, £17

\section{Jeremy Gray}

Most of us know what a Venn diagram is, and many of us will have used them to represent families of objects with overlapping characteristics. Some of us will have 


\section{Return of the mummy}

\section{An ancient Egyptian priest has a virtual life at London's British Museum.}

\section{Michael Hopkin}

Three thousand years ago, the people of Karnak, an ancient Egyptian community on the banks of the Nile, embalmed and buried a priest called Nesperennub. They did a good job - he has remained mummified ever since and is unlikely ever to be unwrapped. But now we can at last say hello, face to virtual face, thanks to a project that blends archaeology, medical technology and computer graphics.

The practice of unwrapping - and thus destroying - mummies was rife when Nesperennub was delivered into the collection of London's British Museum in 1899. But Nesperennub has survived to become the centrepiece of Mummy: the Inside Story, an exhibition that runs at the museum until January 2005. The exhibition showcases the museum's new non-invasive approach to studying wrapped mummies, using computerized tomography (CT) scanners of the sort common in hospitals.

John Taylor, the museum's egyptologist who led the project, teamed up with the imaging company Silicon Graphics (SGI) to reconstruct Nesperennub from some 1,500 CT images, as shown here. This is the first time that CT scans have been used to reveal a mummy's intimate details previous attempts using X-rays provided only sketchy images.

The new technique has sparked fresh speculation about Nesperennub's life and death, and confirms some long-held theories about the mummification process. The brain is missing, for example, as are the fine bones of the nasal cavity - a vindication of archaeologists' belief that the brain was removed by pulling it through the nose. Elsewhere, vital organs such as the lungs and liver have been removed, wrapped and replaced. Nesperennub's body is adorned with amulets, presumably to safeguard his passage to the world of the gods.

Judging by the wear and tear on his backbone, Nesperennub lived into his forties. And as his 1.62metre stature attests, he was probably well fed. But life wasn't an endless round of pleasure: it seems he had a large abscess under one of his teeth; and a hole in his skull, apparently made from the inside, hints that he died of a brain tumour. The

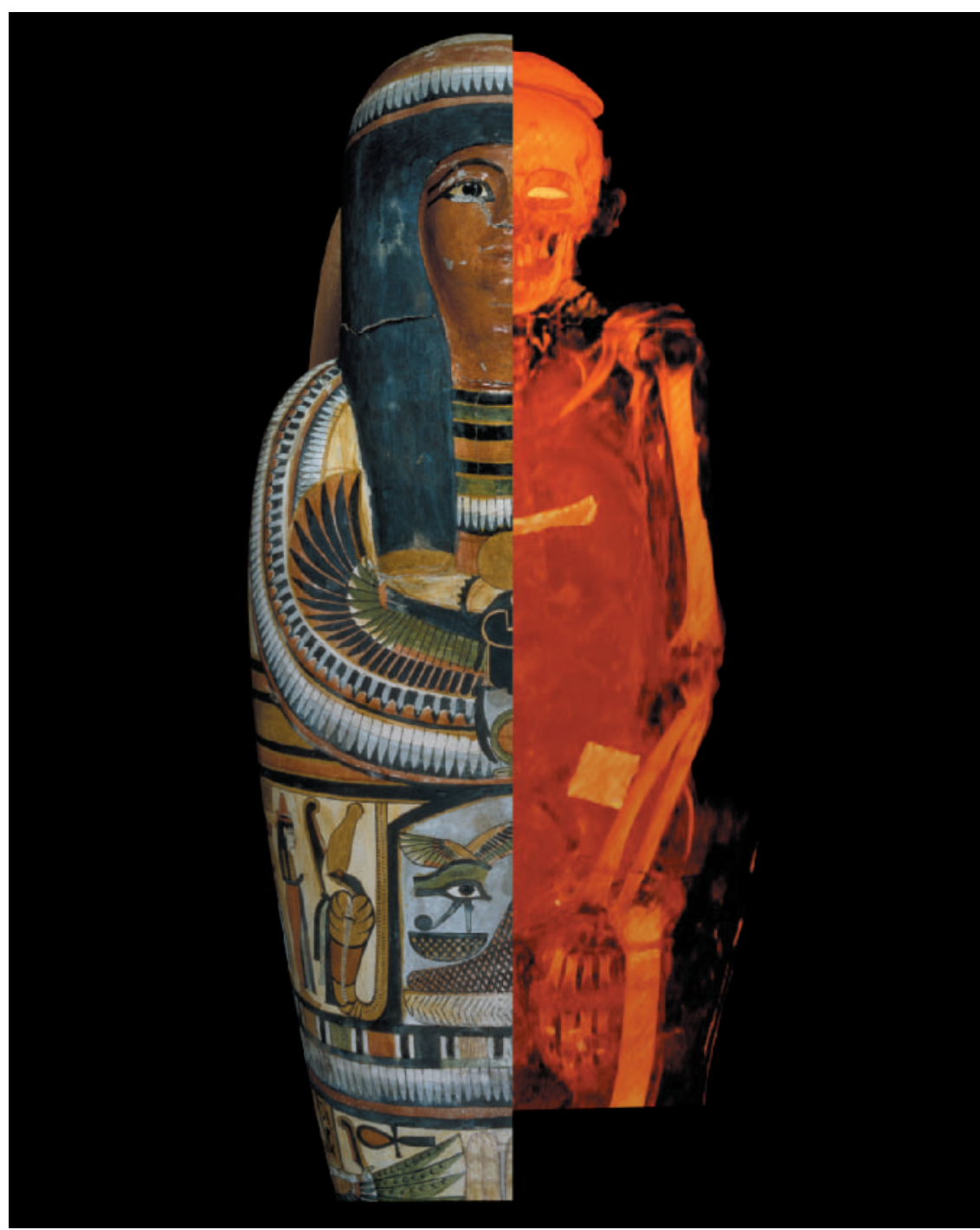

project's members have even created a virtual bust of Nesperennub, although they admit that facial reconstructions always involve a measure of guesswork.

Most intriguingly of all, however, Nesperennub has a clay bowl seemingly stuck to the top of his head. Unlike the rest of his adornments, it is not ornately carved. Taylor speculates that it may have been placed there to catch drips of embalming resin and accidentally become stuck fast.
Visitors to the museum can ponder this possibility as they watch a film featuring computer reconstructions and scenes from everyday life in Karnak, as envisaged by the project team. Entertaining, yes. But Taylor emphasizes that the technique is first and foremost a research tool - the museum has about 100 mummies in its collection, and plans to bring many of them back to virtual life. Michael Hopkin writes for news@nature.com,

Nature's online news service. noticed that what works for three sets seems to work less well for four, and might break down entirely for five or more sets, when perhaps our enthusiasm for classification begins to fade. Is there an elegant way of drawing a Venn diagram showing all possible intersections of, say, seven sets, and is it systematic - does it build routinely to an arbitrary number of sets?

What Cogwheels of the Mind triumphantly shows is that the answer to both questions is 'yes'. A.W. F. Edwards not only shows how it can be done, but discusses a variety of different solutions that connect Venn diagrams to significant questions in coding theory. $\mathrm{He}$ also provides a fascinating glimpse into how research into mathematics gets done, and tells a satisfying historical story. And he provides what may be the most important reason for continuing to care about these diagrams: they illuminate the problem of finding maximal embeddings of subgraphs of a hypercube. All this and a great number of mathematically beautiful figures mean that the book deserves to become a minor classic and may well go on to make many friends for mathematics.

Jeremy Gray is at the Centre for the History of the Mathematical Sciences, Open University, Milton Keynes MK7 6AA, UK. 